\title{
Menstrual Fluid Factors Mediate Endometrial Repair
}

\author{
Lois A. Salamonsen* \\ Centre for Reproductive Health, Hudson Institute of Medical Research and Department of Molecular and Translational \\ Science, Monash University, Clayton, VIC, Australia
}

\section{OPEN ACCESS}

Edited by:

Philippa Saunders,

University of Edinburgh,

United Kingdom

Reviewed by:

Jan Brosens,

University of Warwick,

United Kingdom

Jacqueline Maybin,

University of Edinburgh,

United Kingdom

*Correspondence:

Lois A. Salamonsen lois.salamonsen@hudson.org.au orcid.org/0000-0003-0558-7325

Specialty section:

This article was submitted to

Gynecology,

a section of the journal

Frontiers in Reproductive Health

Received: 20 September 2021 Accepted: 15 November 2021 Published: 21 December 2021

Citation:

Salamonsen LA (2021) Menstrual Fluid Factors Mediate Endometrial Repair. Front. Reprod. Health 3:779979. doi: 10.3389/frph.2021.779979
Menstruation is a process whereby the outer functionalis layer of the endometrium is shed each month in response to falling progesterone and estrogen levels in a non-conception cycle. Simultaneously with the tissue breakdown, the surface is re-epithelialized, protecting the wound from infection. Once menstruation is complete and estrogen levels start to rise, regeneration progresses throughout the proliferative phase of the cycle, to fully restore endometrial thickness. Endometrial repair is unique compared to tissue repair elsewhere in the adult, in that it is rapid, scar-free and occurs around 400 times during each modern woman's reproductive life. The shedding tissue and that undergoing repair is bathed in menstrual fluid, which contains live cells, cellular debris, fragments of extracellular matrix, activated leukocytes and their products, soluble cellular components and extracellular vesicles. Proteomic and other analyses have revealed some detail of these components. Menstrual fluid, along with a number of individual proteins enhances epithelial cell migration to cover the wound. This is shown in endometrial epithelial and keratinocyte cell culture models, in an ex vivo decellularized skin model and in pig wounds in vivo. Thus, the microenvironment provided by menstrual fluid, is likely responsible for the unique rapid and scar-free repair of this remarkable tissue. Insight gained from analysis of this fluid is likely to be of value not only for treating endometrial bleeding problems but also in providing potential new therapies for poorly repairing wounds such as those seen in the aged and in diabetics.

Keywords: menstrual fluid, endometrial repair, Re-epithelialization, scar-free repair, endometrium

\section{INTRODUCTION}

The endometrium, the inner lining of the uterus, provides the maternal support for embryo development and undergoes remarkable remodeling on a cyclical basis. In humans and a few other species including old world primates, the endometrium develops more extensively during each menstrual cycle than in other placental mammals. In particular the process of decidualization, which provides the basis for the decidua of pregnancy, is initiated whether or not the cycle is one in which conception occurs. As this process is not reversible, the endometrium is shed in the process known as menstruation, then fully repaired and reconstructed during the subsequent cycle. Importantly, in contrast to most adult wounds, the endometrium repairs very rapidly (days) without scarring (otherwise seen only in fetal tissues) and occurs over 400 times during a woman's reproductive lifespan. Most aspects of menstruation are discussed elsewhere in this volume. The focus of this article is the role of menstrual fluid (MF) in the scar-free repair of the endometrium. 


\section{Menstruation: Endometrial Shedding}

Understanding the cellular and molecular events of menstruation provides insights critical to understand the likely composition of menstrual fluid.

During menstruation, the outer functional layer of the endometrium is shed in a piecemeal manner, with breakdown and rapid repair occurring simultaneously at adjacent sites (1, 2 ). Shedding is finely controlled so that while most or all of the functional layer is shed, the basalis remains in situ. reepithelialization occurs rapidly but it is from the basalis that the full thickness endometrium subsequently regenerates (3). What is not yet known is the mechanism preventing degradation of the basalis although it has been proposed that the horizontal network of glands forming a "rhizome-like" layer may be limiting (4).

Menstruation is considered to be a highly regulated inflammatory response to progesterone withdrawal. Initiation of menstrual events occurs in the decidualized endometrial stromal cells, which express progesterone receptors and hence sense hormone withdrawal. These cells initiate a sequence of interdependent inflammatory events including nuclear translocation of NF- $\kappa \mathrm{B}$, a transcription factor that regulates both innate and adaptive immune responses. NF- $\kappa \mathrm{B}$ signaling induces the progressive production of many inflammatory cytokine and chemokine mediators, increased prostaglandin synthetic enzymes and production of pro-inflammatory prostaglandins (5). The released chemokines recruit and activate leukocytes (predominantly granulocytes) into the endometrium. Variable numbers and types of immune cells are present in the functional layer throughout the menstrual cycle, but are in low abundance until the pre-menstrual stimulus that initiates a massive and highly selective influx of leukocytes. Perimenstrually, these comprise up to $50 \%$ of the total cells population. $6-15 \%$ of all nucleated cells in the stromal compartment of the functional endometrial layer are neutrophils, the same abundance as for macrophages $\left(\mathrm{CD}_{16}{ }^{+}\right)$and uterine natural killer $(\mathrm{NK})$ cells $\left(\mathrm{CD}^{+} 6^{+} / \mathrm{CD}^{-} 6^{-}\right)$but eosinophils, mast cells (both 3-5\%) and $T$ lymphocytes (1-2\%) are less common [review; (6)]. Importantly, these cells are phenotypically different from their counterparts in peripheral blood indicating the effects of the local microenvironment. For example, production of active elastase is much reduced and alpha1-anti-trypsin highly elevated in endometrial neutrophils compared with peripheral blood neutrophils (6). Together these leukocytes, many detectable in activated forms, establish an inflammatory cascade which results in tissue breakdown. These complex phenotypic changes in a highly dynamic physiological setting in women, severely limit investigation of their individual functions. It is also possible that cellular senescence, particularly of the decidualized stromal cells, plays a role; this has been recently described in human endometrial assembloids (7) but any contribution to menstruation remains to be established.

Importantly for the tissue breakdown at menstruation, each non-migratory cell in the functionalis epithelial, stromal, decidualized stromal cells $(5,8)$ also directly or indirectly responds to progesterone withdrawal by releasing an array of proteolytic enzymes including matrix metalloproteinases, plasminogen activator family members and other molecules, with considerable interactions occurring that initiate self-activating cascades. These can be between products of both resident cell and leukocytes. For example, in vivo, endometrial-derived immune cells produce a wide range of enzymes important for other cell activation (e.g., degranulation of eosinophils induced by neutrophil elastase), or molecular processing such as conversion of latent to active matrix metalloproteinases by elastase or cathepsin G. These combined actions result in degradation of the extracellular matrix (ECM) and tissue breakdown $(9,10)$. Tissue shedding during menstruation is piecemeal; fragments of endometrial tissue can be found in menstrual fluid (MF) along with single endometrial cells, blood, and ECM debris.

\section{Endometrial Repair}

Endometrial repair is uniquely scar-free, is initiated almost immediately as shedding starts and is complete by the time bleeding ceases (up to 8 days) (11). Degrading tissue and re-epithelializing sites are seen adjacent to one another in the menstruating tissue by histology and scanning electron microscopy (1, 2) and once bleeding ceases (when reepithelialization is complete), regeneration of the entire tissue thickness is initiated. The rapid re-epithelialization serves to protect the tissue from bacterial invasion as it regenerates. Initially, re-epithelialization is observed as migration of epithelial cells from the exposed stumps of glands and these can be seen by scanning electron microscopy to expand outwards to meet similar cells from other glands or those migrating from any intact remaining epithelium $(2,12)$. Repair of damage to transverse sub-epithelial endometrial arterioles within the stroma and to spiral arterioles, which can be severely injured during tissue breakdown, occurs concomitant with re-epithelialization. However, full regeneration of the endometrium is primarily if not entirely from stem/progenitor cells present in the basalis layer (which is not shed). This regeneration requires estrogen action, and is complete by the time of ovulation, $\sim 14$ days after the start of menstruation, and 9 days following cessation of bleeding and full re-epithelialization (13). Data has indicated that mesenchymal to epithelial cell differentiation (EMT) contributes to restoration of the luminal epithelium at least in mice (14, 15); however, recent in vivo cell fate-tracing studies in mice have found no evidence for EMT in endometrial repair [(16), reviewed in (13)]. Evidence for an EMT contributing to human endometrial repair should be further examined.

Most adult wounds repair with scar formation, which may impair function and inhibit further growth whereas repair of the endometrium (and of wounds in fetal tissue), is scar free. There are also differences between wounds in the adult oral cavity and elsewhere in the body (17), largely due to unique mediators in saliva. Wound healing in general involves a complex interplay between numerous cell types, cytokines, mediators and the vascular system. Wounding in all tissues is accompanied by an influx of inflammatory cells, starting with neutrophils and their local release of chemokines that attract other leukocytes to the wound site. These cells together release a range of mediators and cytokines that promote reepithelialization, angiogenesis and thrombosis. The fibroblasts in turn secrete ECM components that provide scaffolding for 
the cellular events (18). The scar tissue that forms in most adult tissues, results from the formation and extension of fibrous tissue (fibrogenesis) derived primarily from stromal cells (19). However, the healed endometrium is without obvious fibrosis. Furthermore, while repair of most wounds takes 4-6 weeks, repair of the endometrial surface is generally complete within 5 days.

Since in most tissues, stromal cells are the major effectors of scarring, it must be assumed that endometrial stromal cells derived from stem/progenitor cells during endometrial regeneration are differently programmed. Given that reepithelialization to cover the endometrial surface is so rapid, the stem/progenitor cells are likely brought into play more quickly than in other tissues. Interestingly, transforming growth factor (TGF) $\beta 1$, a factor that strongly promotes the myofibroblast phenotype, is elevated in menstrual fluid compared with peripheral blood and could theoretically act on endometrial stromal cells in vitro to differentiate them into myofibroblasts (19). Since this does not occur, it must be that in vivo, either the TGF $\beta 1$ must be non-functional, or other regulatory stimuli must prevent such differentiation to prevent scarring. Importantly, menstrual fluid, added to cultures of stromal cells of adipose and dermal origin, suppresses their transition to myofibroblasts as it does with endometrial stromal cell cultures, supporting this contention (19). However, the active suppressive factor/s remain to be identified.

\section{Uterine Fluid and Menstrual Fluid}

Given that endometrial repair occurs rapidly within a microenvironment of menstrual fluid, evidence is now emerging that menstrual fluid contains bioactive factors that promote scar-free repair. What is currently known of these components and their potential actions will be discussed below. However, it is important to set the scene by first considering the composition of uterine fluid which changes throughout the menstrual cycle.

\section{Uterine Fluid}

During the menstrual cycle, a small volume of fluid is always present within the uterine cavity and its components (both soluble and extracellular vesicles) vary between the proliferative and secretory phases and between fertile and infertile women. A number of major soluble components that appear in uterine fluid even outside of menses, are transudated from blood, although this is very selective. Differential protein composition between peripheral blood and uterine fluid was first shown clearly in the 1980's with the advent of two-dimensional gel (2D-DIGE) analyses $(20,21)$. These studies highlighted proteins specific to uterine fluid and identified differences in fluid composition between the proliferative and secretory phases. Subsequently, 2D-DIGE identified a number of major serum proteins in uterine fluid (human serum albumin, transferrin, immunoglobulins (Ig)G and A, antitrypsin, haptoglobin and hemoglobin), which could be removed prior to further analyses, improving sensitivity for subsequent analysis of the remaining soluble factors (22-24). Such depletion at least doubled the number of proteins that could be identified (24) and which differed between receptive and non-receptive states in fertile and infertile women (23).

Other soluble components of uterine fluid are contributed from peritoneal and tubal fluids, and from endometrial epithelial cell secretions, particularly those of the glands. Uterine fluid proteins, including cytokines and chemokines have been examined using protein array technologies applied to samples taken across the menstrual cycle and between fertile and infertile women $(22,23,25-27)$, with $>30$ cytokines, chemokines and growth factors being identified. These include interleukin (IL)-1 $\beta$, IL-6, IL-12, IL-17, IL-18, tumor necrosis factor (TNF) $\alpha$, macrophage migration inhibitory factor (MIF), eotaxin, monocyte chemotactic protein (MCP) 1, interferon-gamma (IFN $\gamma$ )-inducible protein-10, vascular endothelial growth factor (VEGF), platelet-derived growth factor (PDGF)-AA and chemokine (C-X-C motif) ligand 1-3, all of which are detectable in $>90 \%$ of samples.

There is no correlation between amino acid concentrations in serum and uterine fluid: 18 amino acids have been identified in human uterine fluid, their concentrations being altered by maternal diet. These include asparagine, histidine, serine, glutamine, valine, isoleucine, and leucine (28). In addition, lipids, a range of metabolites [review; (29)], miRNAs [review; (30)], and small extracellular vesicles (sEV) previously known as exosomes $(3,31,32)$, have been identified and/or harvested from uterine fluid obtained from cycling women. These sEVs contain a cohort of miRNAs and proteins, with changes in their proteomes being defined between cycle phases $(3,31)$.

\section{Menstrual Fluid}

Menstrual fluid (MF) is most often harvested into menstrual cups, a relatively non-invasive and convenient method that can be managed at home. The most common time of collection is on the second day of menstruation, when menstrual flow is maximal. Importantly, MF collection using a menstrual cup has proven to be highly reliable and reproducible between women and between cycles (33). Among the components of MF are debris from tissue breakdown, live cells or groups of cells (epithelial, stromal, vascular) released when the surrounding extracellular matrix (ECM) is degraded, activated leukocytes and their products, endometrial stem cells and extracellular vesicles.

Since menstruation is a controlled inflammatory event, resulting in tissue breakdown, MF would be expected to contain many more soluble components than the uterine fluid of the late secretory phase, which immediately precedes menstruation. The additional soluble molecules will be derived from many cellular sources, including endometrial and immune cells (particularly the neutrophils, macrophages, uterine $\mathrm{NK}$ and mast cells, that are abundant in the tissue during menstruation), along with intracellular components of degraded cells. These are likely also to contribute to endometrial repair (summarized in Figure 1), a concept supported by reduced uNK cell numbers in late secretory tissue in women with heavy menstrual bleeding (34). 


\section{stromal fibroblasts}

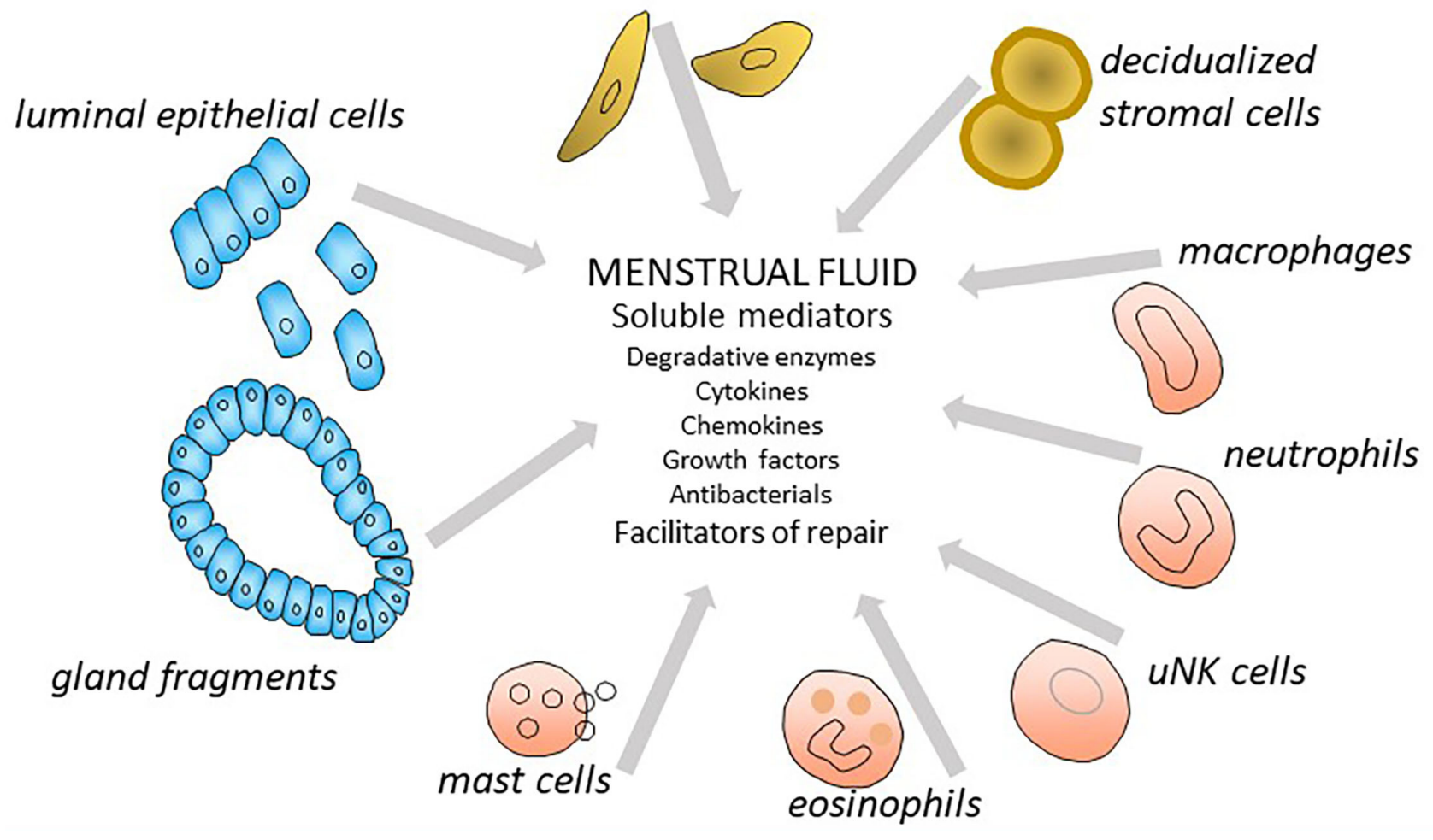

FIGURE 1 | The likely cellular origins of soluble components of menstrual fluid.

\section{Soluble Components of Menstrual Fluid Soluble Contributions From Non-migratory Endometrial Cells}

Soluble components of menstrual fluid have been studied in much less detail than those of uterine fluid. Early studies arose from the need to understand how menstrual bleeding is regulated. Uterine haemostasis differs from that in other organs, in that the endometrial haemostatic plugs are morphologically different and very short lived $(35,36)$. Coagulation and fibrinolytic proteins measured in menstrual fluid supernatant on days 1 and 2 of normal menstruation, showed a virtual absence of thrombin-generating activity and very much higher levels of fibrin-related antigen, active plasmin and plasminogen activator than seen in normal serum, while functionally active $\alpha$-2-antiplasmin was undetectable (37). Disappointingly this data did not provide a pointer to the mechanisms controlling menstrual blood loss. However, prostaglandins (PG) $F_{2} \alpha$ and $E_{2}$, are also present in menstrual fluid, and levels correlate directly with menstrual blood loss (38). Furthermore, a lack of detectable 9-ketoreductase or 9-hydroxydehydrogenase activity indicates there could be interconversion between the two PGs.

Most reproductive hormones do not show a difference between peripheral venous blood and menstrual plasma. However, while menstrual follicle stimulating hormone (FSH), estradiol- $17 \beta$ and progesterone are likely to arise entirely from the peripheral circulation, prolactin (PRL) levels are elevated only in menstrual blood (39), indicating release into the menstrual flow from mid-late secretory endometrium, where PRL is expressed both in the epithelium and in the decidualized stroma (40).

Recent application of state-of-the-art proteomics techniques $(41,42)$ to supernatant from centrifuged menstrual fluid (menstrual plasma) vs. matched peripheral plasma have provided extensive lists of proteins specific to menstrual fluid. While both investigators depleted the samples of abundant serum proteins, Evans additionally enriched samples using a combinatorial peptide ligand library (CPLL), along with capture of heparin and fibronectin binding proteins separately on the depleted samples. The most abundant identified proteins from these two studies are listed in Table 1. Many reflect the state of the endometrium in the late secretory phase when pre-decidual changes are evident with concomitant changes in protein production, including insulin growth factor binding protein (IGFBP)-1, matrix metalloproteinase (MMP)9, galectin 3, glycodelin A, glucose transporter (GLUT)1, IL1 and others (24). However, additional proteins not present before menstruation were identified, reflecting induced protease activity from epithelial and decidualized stromal cells, and factors derived from cells released upon tissue lysis (41). VEGF was also significantly elevated in menstrual fluid vs. peripheral plasma. 
TABLE 1 | Proteins elevated in menstrual fluid vs. peripheral plasma and known to facilitate repair.

\begin{tabular}{|c|c|c|c|}
\hline Protein name & Known as & Previously known actions in repair & References \\
\hline $\begin{array}{l}\text { Neutrophil gelatinase -associated } \\
\text { lipocalin/lipocalin-2 }\end{array}$ & NGAL & Promigratory in epithelial cells & $(43)$ \\
\hline Epidermal fatty acid binding protein-5 & FABP-5 & $\begin{array}{l}\text { Augments peroxisome proliferator-activator receptor } \delta \text { in promoting } \\
\text { proliferation and survival }\end{array}$ & (44) \\
\hline Follistatin-related protein 1 & FSTL-1 & See-saw regulation in wounded skin - inverse relationship with miRNA-198 & $(45)$ \\
\hline $\begin{array}{l}\text { Macrophage migration inhibitory } \\
\text { factor }\end{array}$ & MIF & $\begin{array}{l}\text { Proposed pro and anti-repair actions in skin, probably due to different skin } \\
\text { models tested. }\end{array}$ & $(46,47)$ \\
\hline Secretory leukocyte protease inhibitor & SLPI & Various roles in cell migration depending upon the system & $(24,48)$ \\
\hline Human epididymis protein 4 & HEP4 & migration & (49) \\
\hline S100 proteins & $\begin{array}{l}\text { S100A8 S100A9 } \\
\text { S100A11 }\end{array}$ & $\begin{array}{l}\text { Promote cell migration, but not proliferation } \\
\text { Cell motility }\end{array}$ & $(50,51)$ \\
\hline Lactotransferrin/lactoferrin & LTF & Promotes skin repair & $(52,53)$ \\
\hline Stanniocalcin-1 & STC1 & Angiogenesis & (54) \\
\hline Ninjurin-2 & NINJ2 & Adhesion protein, promotes cell growth & (55) \\
\hline $\begin{array}{l}\text { Neuroblast differentiation-associated } \\
\text { protein }\end{array}$ & AHNAK & migration & $(56)$ \\
\hline Osteopontin & OPN & Cell survival, proliferation, migration & (57) \\
\hline Galectin & Gal1 Gal3 & $\begin{array}{l}\text { Migration, proliferation } \\
\text { Repair }\end{array}$ & $(58,59)$ \\
\hline Macrophage inhibitory factor & MIF & $\begin{array}{l}\text { Pro-inflammatory } \\
\text { antibacterial }\end{array}$ & $(60)$ \\
\hline Interleukin 8 & IL8 & Attracts and activates neutrophils & $(60)$ \\
\hline Vascular endothelial growth factor A & VEGF-A & $\begin{array}{l}\text { Neo-angiogenesis, } \\
\text { Re-epithelialization }\end{array}$ & (61) \\
\hline
\end{tabular}

Data derived from (41).

More recently, using a custom magnetic Luminex assay, common inflammatory and repair proteins: secretory leukocyte protein inhibitor (SLPI); lipocalin-2 (NGAL); lactoferrin; follistatin-like 1 (FSTL1); and human epididymis protein-4 (HE4), were identified in $>60 \%$ of menstrual fluid samples analyzed (62), reflecting their previous recognition (41). Interestingly, a negative association between menstrual fluid volume and abundance of some of these proteins (HE4, galectin-1, MIF, SLPI, NGAL, and FSTL1) was revealed following normalization for total menstrual fluid protein $(\mathrm{ng} / \mathrm{mg})$. It may be that as menstrual fluid volume increases, other endometrial- or peripheral-derived proteins may similarly increase, thus diluting the proteins of particular interest. Interestingly, many of the menstrual fluid factors listed in Table 1, positively cross reference with those in Senequest (https://Senequest.net/) which contains factors involved in cellular senescence.

Matrix degrading enzymes, including a number of matrix metalloproteinases (MMP), are major players at menstruation, and are released from endometrial epithelial and decidualized stromal cells specifically as progesterone levels fall and also from activated leukocytes (see below). These are accompanied by the release of potential activators and tissue inhibitors of MMPs (TIMPs) which are abundant in endometrial tissue and which together tightly control MMP actions $(63,64)$. Although only MMP9 was identified in a proteomic analysis of menstrual fluid (41), menstrual serum showed a pattern of MMP activity on zymography different from that of peritoneal fluid while both MMP-7 and MMP-9 were identified by Western blot uniquely in menstrual serum (65). While MMPs are very important for tissue breakdown, they also play roles in tissue repair largely due to their broad protease activities not related to matrix degradation. Some but not all actions on repair, have been validated in individual genetically-modified mouse models including those null for MMP1, MMP8, MMP9, MMP10, and MMP14 (66). In other repair situations, epithelialderived MMPs facilitate cell migration by affecting cell-matrix adhesion. For example, in mucosal epithelia, MMP7 facilitates re-epithelialization by cleaving different ECM or ECM-associated proteins to affect integrin: matrix adhesion (66). Indeed MMP7deficient mice have the most impairment of re-epithelialization of any MMP-null mice generated to date and show disturbance of the affinity of integrin $\alpha_{2} \beta_{1}$ cell-matrix interactions (67). In human endometrium MMP7 mRNA is highly increased in epithelial and decidual cells at menstruation and remains throughout the new proliferative phase indicating a role in repair and regeneration (68). Active MMP7 is recruited to the plasma membrane of epithelial cells, thus escaping TIMP inactivation and allowing processing of membrane-associated growth factors needed for epithelial repair and proliferation (69). The involvement of MMPs in endometrial repair remains to be determined. 


\section{Soluble Contributions From Immune Cells}

Mononuclear cells isolated from menstrual blood samples are phenotypically similar to the reported phenotype for biopsyderived endometrial cells, and distinct from peripheral blood mononuclear cells [PBMC: (33)] although percentages of NK cells are higher and those of $T$ cells are lower.

Macrophages, neutrophils, mast cells, and eosinophils, all degranulate upon activation, releasing their soluble contents. Importantly, active forms have been identified during menstruation by virtue of the extracellular immunostaining of granular contents (70-72). These granulocytes have more than one type of granule and there are many similarities in granule morphology, granule content, stimulus for degranulation, and granule trafficking, most of which are not well-understood, particularly in the context of the endometrium. However, it is clear that there is considerable overlap between contents of granules from different sources; for example, eosinophils, neutrophils and macrophages all release matrix metalloproteinase 9 at menstruation (70).

While there is a paucity of information on immune cell products in menstrual fluid that may be relevant to endometrial repair, elsewhere, eosinophils produce a number of growth factors, including TGF- $\alpha$ and $-\beta$, fibroblast growth factor (FGF), EGF, PDGF, and VEGF, which participate in angiogenesis and myocardial repair (73). Eosinophils also produce cytokines, in particular IL5 and IL4 which have roles in wound healing and macrophage differentiation. Indeed, mice overexpressing IL5 displayed insufficient production of ECM components and had impaired wound healing. IL4 is essential for differentiation of macrophages toward an M2 phenotype, and regulating myocardial tissue regeneration (74). Uterine NK cells from menstrual fluid produce IFN $\gamma$, granzyme B, and perforin, upon stimulation with IL2 and IL15 (33).

Neutrophils contribute to physiological tissue repair, and seem to be necessary for normal healing at least in part by promoting angiogenesis (75). Furthermore, apoptosis of neutrophils after degranulation provides a powerful stimulus for macrophage differentiation into the anti-inflammatory M2 phenotype, through their production of annexin A1, lipocalin, lactoferrin, and cathelicidin. Neutrophil-derived MMP12 also possesses potent pro-resolving properties (74). Anti-bacterial agents within menstrual fluid including lactotransferrin and NGAL may also play a role in post-menstrual endometrial repair.

Mast cell actions are likewise realized through degranulation and secretion of the granules' content of cytokines or production of lipid mediators, depending on the nature of the stimuli received during activation. Relevant to wound repair, during cardiac tissue re-modeling their main function appears to be associated with regulation of fibrous tissue metabolism (76), and they may both enhance and inhibit post-myocardial fibrosis. Their pro-fibrotic properties are mediated primarily by chymase (present in the uterus only in myometrial mast cells) and tryptase (present in endometrial mast cells) (72), which are identified as activators of TGF $\beta$ and angiotensin II, well-known promoters of fibroblast activity. Mast cells also produce and secrete anti-fibrotic mediators such as IL10, IL13, CXCL10, and VEGFA (76).

\section{Endometrial Stem Cells in Menstrual Fluid}

Cells with mesenchymal stem cell properties have been identified in menstrual blood. Following depletion of red blood cells and $\mathrm{CD}_{4} 5^{+}$leukocytes from menstrual fluid, endometrial stem/progenitor cells including clonogenic endometrial cells, sushi domain containing- $2^{+}\left(\right.$SUSD2 $\left.^{+}\right)$mesenchymal stem cells and $\mathrm{N}$-cadherin ${ }^{+}\left(\mathrm{NCAD}^{+}\right)$epithelial progenitor cells, have been isolated $(62,77,78)$, with limited variability across menstrual cycles (62). These cells are not present in peripheral blood. They are generally retrieved from the menstrual fluid as plastic adherent cells and show differences in immunophenotype, proliferation and differentiation capacities from bone marrowderived mesenchymal stem cells. Since these cells can be reliably purified from menstrual fluid, they may provide a useful noninvasive source of stem/progenitor cells for clinical application. However, isolation protocols and culture conditions must be standardized to maximize their potential. Importantly a serumfree culture protocol has been established that contains a TGF $\beta$ receptor inhibitor, that prevents spontaneous differentiation, apoptosis, and senescence of the clonogenic SUSD2 ${ }^{+}$population and enhances their potency (77).

\section{Extracellular Vesicles in Menstrual Fluid}

Small extracellular vesicles (sEV) previously termed exosomes, are released from all cells. They act as carriers of "cargo" of bioactive molecules including miRNA, proteins and lipids, which they deliver to specific target cells: the phospholipid membranes of the sEV protect the "cargo" from extracellular degradation. Importantly the proteomes of endometrial epithelial cell sEV depend upon the hormonal environment of the cells of their origin (estrogen or estrogen plus progesterone), but are substantially different from those of the cellular proteomes (79). Endometrial-derived $\mathrm{sEV}$ are present in uterine fluid (3, $31,32)$, although their role in endometrial repair has not yet been examined. A number of pre-clinical studies have evaluated effects of sEVs on the wound-healing process [review; (80)]. For example, in a mouse burn model, sEV derived from human menstrual blood -derived mesenchymal stem cells injected close to the site of injury, enhanced wound closure and increased neoangiogenesis was evident (81). Furthermore, sEV derived from human umbilical cord blood mesenchymal stem cells stimulate regenerative wound healing via TGF $\beta$ receptor inhibition (82). Likewise, EVs derived from normal resident lung epithelial cells, appear to possess anti-fibrotic properties, inhibit TGF $\beta$-WNT cross talk and offer a promising anti-fibrotic treatment (83). If similar mediators are contained in sEV in menstrual fluid, this could provide an explanation for the lack of scarring during endometrial repair.

\section{Functional Analyses of Menstrual Fluid and Its Soluble Components}

The most difficult task following omics analyses is subsequent determination of the likely functions of the large number of identified molecules. In the context of menstrual fluid proteomics, Evans et al., (41), examined actions of the entire soluble fraction of menstrual fluid in a number of biologically relevant repair models. Subsequently, individual fluid molecules, 
selected for their known function in wound repair were applied at concentrations selected from their measured concentrations in menstrual fluid. Endometrial cell cultures (ECC1 cell line) and keratinocyte cell cultures (HaCatT cell line) were chosen for these studies for their similarities to primary endometrial epithelial and primary keratinocytes. Classic wounding assays were applied to overconfluent cultures which were "wounded" by vacuum suction followed by imaging and analysis using imaging software daily for 3 days. Real-time label-free analysis of adhesion and proliferation using the xCelligence system (ACEA Biosciences, San Diego CA, USA) was also applied to cultures of similarly treated ECC-1 and HaCatT cells. In more physiological assays, ex vivo de-epidermized dermis (DED) pre-parations (84) were prepared and cultured for 4 or 8 days in the presence or absence of menstrual fluid. The area of migration of keratinocytes across the DED was quantified, then tissues were processed and embedded for histological examination and the thickness of both cornified and cellular layers were measured. Finally, in vivo, a porcine superficial wound model in juvenile pigs, in which the wounds were created by dermatome, was treated with wound dressings containing either peripheral plasma or menstrual fluid. Dressings were changed at days 3 and 5, with simultaneous imaging and quantification of re-epithelialization until day 7 when healing in such juvenile models is generally complete. By 5 days, re-epithelialization was significantly enhanced; wound area was slightly decreased; epidermal thickness was moderately increased; and number of hairs per-section was moderately increased. The latter three did not reach significance in the limited number of wounds approved by the ethics committee.

An important conclusion from these investigations is that factors in menstrual fluid advance the initial migratory phase of healing, a key difference from current skin repair treatments that stimulate epithelial proliferation, while vascular repair agents in menstrual fluid (including VEGF) will likely play roles in the initial repair of the vasculature and subsequent angiogenesis (41). Regrettably, this study did not include menstrual fluid factors with no known role in repair processes. These remain to be tested and may prove a potential "gold-mine" of new treatments for wound repair.

\section{Endometrial Vascular Repair}

Simultaneously with re-epithelialization, rapid repair of the open blood vessels must take place to stop the bleeding, some 5 days after menstruation starts. While experimental evidence for angiogenesis at this time of the cycle is lacking, circumstantial evidence indicates its likelihood. Menstrual fluid contains the potent angiogenic factor VEGF-A (85), (41), and this is markedly reduced in women with menorrhagia (85). Interestingly, in the rhesus macaque, a naturally menstruating primate, blockage of VEGF action with VEGF Trap, a potent VEGF blocker inhibited new blood vessel development and re-epithelialization of the denuded surface during menstruation (61). Further in a mouse model of menstruation, similar blockade of VEGF action delayed repair of the denuded endometrial surface and inhibited new blood vessel development (61). HIF-1 $\alpha$, a transcription factor known as the master regulator of the cellular response to hypoxia, can regulate VEGF by directly binding the VEGF pro-motor at least in macrophages (86) and thus hypoxia, may thus contribute to endometrial vascular repair. Indeed, women with prolonged menstrual bleeding have decreased endometrial HIF- $1 \alpha$ during menstruation and the long bleeding period that follows. However, evidence for the presence of hypoxia during menstruation and repair is mixed (87), review:

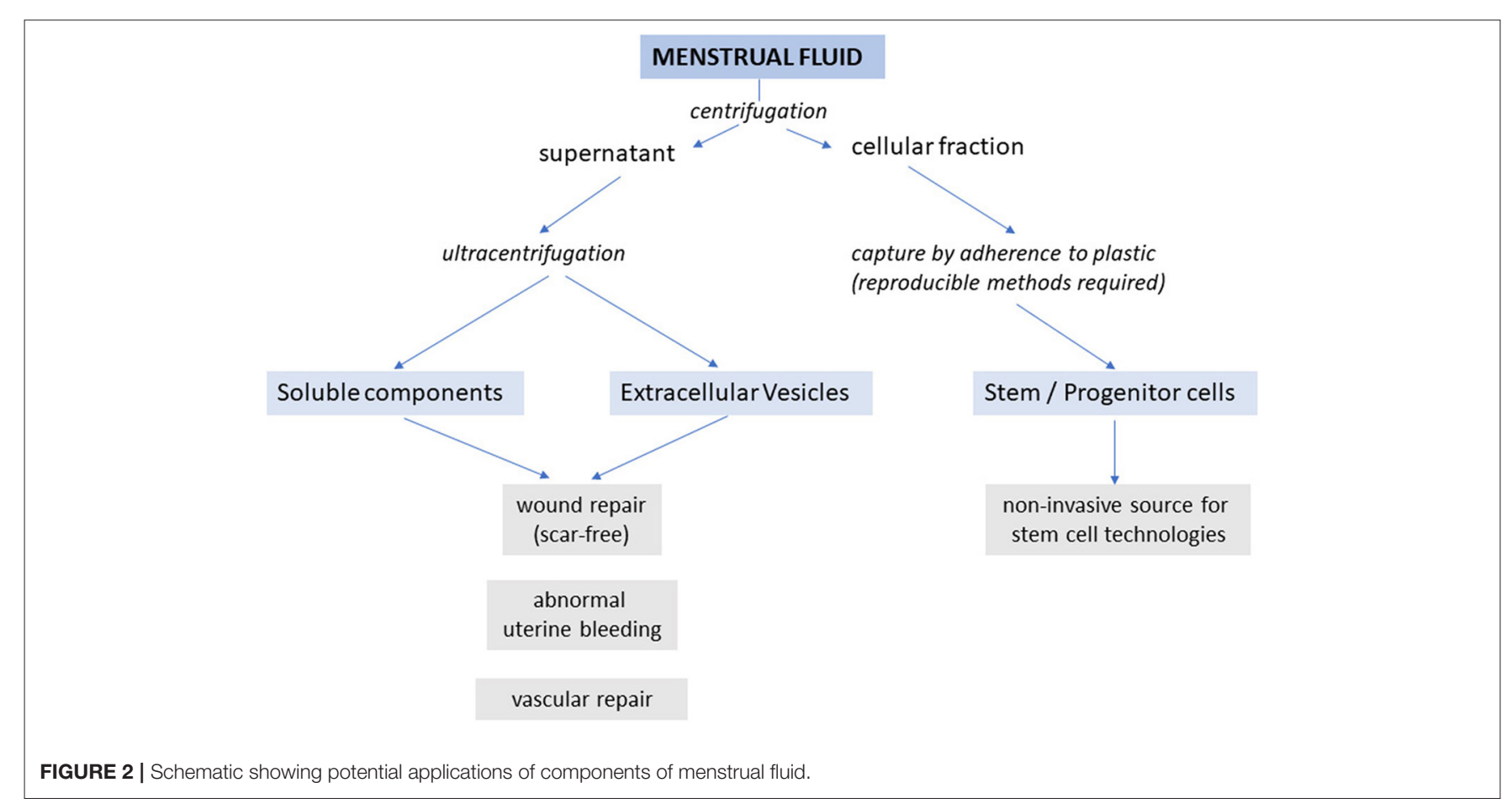


(88), and any role of HIF-1 in endometrial repair needs to be confirmed.

\section{Endometrial Regeneration After Menses}

By the time menses has ceased, the wounded surface is essentially "repaired", covered by a new luminal epithelium with junctional complexes making a tight protective surface, that shields the underlying tissue from infection. During the next 10 or so days (cycle proliferative phase) and as estrogen levels rise, endometrial thickness and the full cohort of cellular structures, including glands, stroma, vascular structures and extracellular matrix (both interstitial and basal lamina) is regenerated through massive cellular proliferation in the growing functional layer. Current knowledge of this regeneration process has recently been detailed (13) and will not be further discussed here.

\section{CONCLUSIONS}

Rapid scar-free repair of the endometrium following menstruation is essential given that it occurs some 400 times during most women's reproductive lives and provides the basis for the subsequent regeneration and differentiation of the endometrium and its attainment of receptivity for embryo implantation in the new cycle. It is now indisputable that the microenvironment provided by menstrual fluid drives effective endometrial repair. Recent advances in analyses of menstrual fluid components has provided some insight but just which are the most important factors, soluble or those delivered to the damaged surface in extracellular vesicles, remains to be

\section{REFERENCES}

1. Garry R, Hart R, Karthigasu KA, Burke C. A re-appraisal of the morphological changes within the endometrium during menstruation: a hysteroscopic, histological and scanning electron microscopic study. Hum Reprod. (2009) 24:1393-401. doi: 10.1093/humrep/dep036

2. Ludwig H, Spornitz UM. Microarchitecture of the human endometrium by scanning electron microscopy: menstrual desquamation and remodeling. Ann N Y Acad Sci. (1991) 622:28-46. doi: 10.1111/j.1749-6632.1991.tb37848.x

3. Rai A, Poh QH, Fatmous M, Fang H, Gurung S, Vollenhoven B, et al. Proteomic profiling of human uterine extracellular vesicles reveal dynamic regulation of key players of embryo implantation and fertility during menstrual cycle. Proteomics. (2021) 21:e2000211. doi: 10.1002/pmic.202000211

4. Yamaguchi $M$, Yoshihara K, Suda K, Nakaoka H, Yachida N, Ueda $\mathrm{H}$, et al. Three-dimensional understanding of the morphological complexity of the human uterine endometrium. iScience. (2021) 24:102258. doi: 10.1016/j.isci.2021.102258

5. Evans J, Salamonsen LA. Inflammation, leukocytes and menstruation. Rev Endocr Metab Disord. (2012) 13:277-88. doi: 10.1007/s11154-012-9223-7

6. Salamonsen LA, Lathbury LJ. Endometrial leukocytes and menstruation. Hum Reprod Update. (2000) 6:16-27. doi: 10.1093/humupd/6.1.16

7. Rawlings TM, Makwana K, Taylor DM, Molè MA, Fishwick KJ, Tryfonos $\mathrm{M}$, et al. Modelling the impact of decidual senescence on embryo implantation in human endometrial assembloids. Elife. (2021) 10:e69603. doi: 10.7554/eLife.69603

8. Salamonsen LA, Butt AR, Hammond FR, Garcia S, Zhang J. Production of endometrial matrix metalloproteinases, but not their tissue inhibitors, is modulated by progesterone withdrawal in an in vitro model for menstruation. J Clin Endocrinol Metab. (1997) 82:1409-15. doi: 10.1210/jc.82. 5.1409 determined. Importantly menstrual fluid has the potential to provide factors for scar-free rapid wound repair, and to treat abnormal uterine bleeding (Figure 2).

\section{AUTHOR CONTRIBUTIONS}

The author confirms being the sole contributor of this work and has approved it for publication.

\section{FUNDING}

LS and her laboratory have been funded extensively by Fellowships, Program and Project grants from the Australian National Health and Medical Research Council. Research at the Hudson Institute of Medical Research is funded in part by a State Government of Victoria Infrastructure support program.

\section{ACKNOWLEDGMENTS}

The author thanks all her colleagues and doctoral students over the past 30 years, who have contributed to building up the knowledge summarized herein. In particular, the ground-breaking work of Dr. Jemma Evans for proteomic analysis of menstrual fluid and functional studies of individual proteins, Dr. David Greening's collaboration on endometrial EVs, and Dr. David Woolley whose collaboration and insights first introduced me to the field of matrix metalloproteinases and leukocyte contributions to tissue re-modeling.

9. Henriet P, Gaide Chevronnay HP, Marbaix E. The endocrine and paracrine control of menstruation. Mol Cell Endocrinol. (2012) 358:197-207. doi: 10.1016/j.mce.2011.07.042

10. Salamonsen LA, Woolley DE. Menstruation: induction by matrix metalloproteinases and inflammatory cells. J Reprod Immunol. (1999) 44:1-27. doi: 10.1016/S0165-0378(99)00002-9

11. Munro MG, Critchley HO, Fraser IS. The FIGO systems for nomenclature and classification of causes of abnormal uterine bleeding in the reproductive years: who needs them? Am J Obstet Gynecol. (2012) 207:259-65. doi: 10.1016/j.ajog.2012.01.046

12. Ferenczy A. Studies on the cytodynamics of human endometrial regeneration. I Scanning electron microscopy. Am J Obstet Gynecol. (1976) 124:64-74. doi: 10.1016/0002-9378(76)90013-2

13. Salamonsen LA, Hutchison JC, Gargett CE. Cyclical endometrial repair and regeneration. Development. (2021) 148:dev199577. doi: 10.1242/dev.199577

14. Cousins FL, Murray A, Esnal A, Gibson DA, Critchley HO, Saunders PT. Evidence from a mouse model that epithelial cell migration and mesenchymal-epithelial transition contribute to rapid restoration of uterine tissue integrity during menstruation. PLoS ONE. (2014) 9:e86378. doi: 10.1371/journal.pone.0086378

15. Patterson AL, Pru JK. Long-term label retaining cells localize to distinct regions within the female reproductive epithelium. Cell Cycle. (2013) 12:288898. doi: $10.4161 /$ cc. 25917

16. Ghosh A, Syed SM, Kumar M, Carpenter TJ, Teixeira JM, Houairia N, et al. In vivo cell fate tracing provides no evidence for mesenchymal to epithelial transition in adult fallopian tube and uterus. Cell Rep. (2020) 31:107631. doi: 10.1016/j.celrep.2020.107631

17. Brand HS, Ligtenberg AJ, Veerman EC. Saliva and wound healing. Monogr Oral Sci. (2014) 24:52-60. doi: 10.1159/000358784

18. Wallace HA, Basehore BM, Zito PM. Wound Healing Phases. Treasure Island, FL: StatPearls Publishing LLC (2021). 
19. Eremichev R, Kulebyakina M, Alexandrushkina N, Nimiritsky P, Basalova $\mathrm{N}$, Grigorieva O, et al. Scar-free healing of endometrium: tissue-specific program of stromal cells and its induction by soluble factors produced after damage. Front Cell Dev Biol. (2021) 9:616893. doi: 10.3389/fcell.2021.6 16893

20. MacLaughlin DT, Richardson GS. Analysis of human uterine luminal fluid proteins following radiolabeling by reductive methylation: comparison of proliferative and secretory phase samples. Biol Reprod. (1983) 29:733-42. doi: 10.1095/biolreprod29.3.733

21. MacLaughlin DT, Santoro NF, Bauer HH, Lawrence D, Richardson GS. Twodimensional gel electrophoresis of endometrial protein in human uterine fluids: qualitative and quantitative analysis. Biol Reprod. (1986) 34:579-85. doi: 10.1095/biolreprod34.3.579

22. Hannan NJ, Stephens AN, Rainczuk A, Hincks C, Rombauts LJ, Salamnsen LA. 2D-DiGE analysis of the human endometrial secretome reveals differences between receptive and nonreceptive states in fertile and infertile women. J Proteome Res. (2010) 9:6256-64. doi: 10.1021/pr1004828

23. Hannan NJ, Paiva P, Meehan KL, Rombauts LJ, Gardner DK, Salamonsen LA. Analysis of fertility-related soluble mediators in human uterine fluid identifies VEGF as a key regulator of embryo implantation. Endocrinology. (2011) 152:4948-56. doi: 10.1210/en.2011-1248

24. Choi JS, Kim JD, Yoon HS, Cho YW. Full-thickness skin wound healing using human placenta-derived extracellular matrix containing bioactive molecules. Tissue Eng Part A. (2013) 19:329-39. doi: 10.1089/ten.tea.2011.0738

25. Boomsma CM, Kavelaars A, Eijkemans MJ, Amarouchi K, Teklenburg G, Gutknecht D, et al. Cytokine profiling in endometrial secretions: a noninvasive window on endometrial receptivity. Reprod Biomed Online. (2009) 18:85-94. doi: 10.1016/S1472-6483(10)60429-4

26. Scotchie JG, Fritz MA, Mocanu M, Lessey BA, Young SL. Proteomic analysis of the luteal endometrial secretome. Reprod Sci. (2009) 16:883-93. doi: $10.1177 / 1933719109337165$

27. Salamonsen LA, Edgell T, Rombauts LJ, Stephens AN, Robertson DM, Rainczuk A, et al. Proteomics of the human endometrium and uterine fluid: a pathway to biomarker discovery. Fertil Steril. (2013) 99:1086-92. doi: 10.1016/j.fertnstert.2012.09.013

28. Kermack AJ, Finn-Sell S, Cheong YC, Brook N, Eckert JJ, Macklon NS, et al. Amino acid composition of human uterine fluid: association with age, lifestyle and gynaecological pathology. Hum Reprod. (2015) 30:917-24. doi: 10.1093/humrep/dev008

29. Bracewell-Milnes T, Saso S, Abdalla H, Nikolau D, Norman-Taylor J, Johnson $\mathrm{M}$, et al. Metabolomics as a tool to identify biomarkers to predict and improve outcomes in reproductive medicine: a systematic review. Hum Reprod Update. (2017) 23:723-36. doi: 10.1093/humupd/dmx023

30. Zhou W, Dimitriadis E. Secreted microRNA to predict embryo implantation outcome: from research to clinical diagnostic application. Front Cell Dev Biol. (2020) 8:586510. doi: 10.3389/fcell.2020.586510

31. Ng YH, Rome S, Jalabert A, Forterre A, Singh H, Hincks CL, et al. Endometrial exosomes/microvesicles in the uterine microenvironment: a new paradigm for embryo-endometrial cross talk at implantation. PLoS ONE. (2013) 8:e58502. doi: 10.1371/journal.pone.0058502

32. Li T, Greenblatt EM, Shin ME, Brown TJ, Chan C. Cargo small noncoding RNAs of extracellular vesicles isolated from uterine fluid associate with endometrial receptivity and implantation success. Fertil Steril. (2021) 115:1327-36. doi: 10.1016/j.fertnstert.2020.10.046

33. van der Molen RG, Schutten JH, van Cranenbroek B, ter Meer M, Donckers J, Scholten RR, et al. Menstrual blood closely resembles the uterine immune micro-environment and is clearly distinct from peripheral blood. Hum Reprod. (2014) 29:303-14. doi: 10.1093/humrep/det398

34. Biswas Shivhare S, Bulmer JN, Innes BA, Hapangama DK, Lash GE. Menstrual cycle distribution of uterine natural killer cells is altered in heavy menstrual bleeding. J Reprod Immunol. (2015) 112:88-94. doi: 10.1016/j.jri.2015.09.001

35. Aparicio SR, Bradbury K, Bird CC, Foley ME, Jenkins DM, Clayton JK, et al. Effect of intrauterine contraceptive device on uterine haemostasis: a morphological study. Br J Obstet Gynaecol. (1979) 86:314-24. doi: 10.1111/j.1471-0528.1979.tb11262.x

36. Christiaens GC, Sixma JJ, Haspels AA. Morphology of haemostasis in menstrual endometrium. Br J Obstet Gynaecol. (1980) 87:425-39. doi: 10.1111/j.1471-0528.1980.tb04573.x
37. Rees MC, Cederholm-Williams SA, Turnbull AC. Coagulation factors and fibrinolytic proteins in menstrual fluid collected from normal and menorrhagic women. Br J Obstet Gynaecol. (1985) 92:1164-8. doi: 10.1111/j.1471-0528.1985.tb03031.x

38. Rees MC, Anderson AB, Demers LM, Turnbull AC. Prostaglandins in menstrual fluid in menorrhagia and dysmenorrhoea. Br J Obstet Gynaecol. (1984) 91:673-80. doi: 10.1111/j.1471-0528.1984.tb04829.x

39. Zhou JP, Fraser IS, Caterson I, Grivas A, McCarron G, Norman T, et al. Reproductive hormones in menstrual blood. J Clin Endocrinol Metab. (1989) 69:338-42. doi: 10.1210/jcem-69-2-338

40. Bryant-Greenwood GD, Rutanen EM, Partanen S, Coelho TK, Yamamoto SY. Sequential appearance of relaxin, prolactin and IGFBP-1 during growth and differentiation of the human endometrium. Mol Cell Endocrinol. (1993) 95:23-9. doi: 10.1016/0303-7207(93)90025-F

41. Evans J, Infusini G, McGovern J, Cuttle L, Webb A, Nebl T, et al. Menstrual fluid factors facilitate tissue repair: identification and functional action in endometrial and skin repair. FASEB J. (2019) 33:584-605. doi: 10.1096/fj.201800086R

42. Yang H, Zhou B, Prinz M, Siegel D. Proteomic analysis of menstrual blood. Mol Cell Proteomics. (2012) 11:1024-35. doi: 10.1074/mcp.M112.018390

43. Gwira JA, Wei F, Ishibe S, Ueland JM, Barasch J, Cantley LG. Expression of neutrophil gelatinase-associated lipocalin regulates epithelial morphogenesis in vitro. J Biol Chem. (2005) 280:7875-82. doi: 10.1074/jbc.M413192200

44. Levi L, Lobo G, Doud MK, von Lintig J, Seachrist D, Tochtrop GP, et al. Genetic ablation of the fatty acid-binding protein FABP5 suppresses HER2-induced mammary tumorigenesis. Cancer Res. (2013) 73:4770-80. doi: 10.1158/0008-5472.CAN-13-0384

45. Sundaram GM, Common JE, Gopal FE, Srikanta S, Lakshman K, Lunny DP, et al. See-saw expression of microRNA-198 and FSTL1 from a single transcript in wound healing. Nature. (2013) 495:103-6. doi: 10.1038/nature11890

46. Gilliver SC, Emmerson E, Bernhagen J, Hardman MJ. MIF: a key player in cutaneous biology and wound healing. Exp Dermatol. (2011) 20:1-6. doi: 10.1111/j.1600-0625.2010.01194.x

47. Kim BS, Pallua N, Bernhagen J, Bucala R. The macrophage migration inhibitory factor protein superfamily in obesity and wound repair. Exp $\mathrm{Mol}$ Med. (2015) 47:e161. doi: 10.1038/emm.2015.26

48. Sugino T, Yamaguchi T, Ogura G, Kusakabe T, Goodison S, Homma Y, et al. The secretory leukocyte protease inhibitor (SLPI) suppresses cancer cell invasion but promotes blood-borne metastasis via an invasion-independent pathway. J Pathol. (2007) 212:152-60. doi: 10.1002/path.2156

49. Lu R, Sun X, Xiao R, Zhou L, Gao X, Guo L. Human epididymis protein 4 (HE4) plays a key role in ovarian cancer cell adhesion and motility. Biochem Biophys Res Commun. (2012) 419:274-80. doi: 10.1016/j.bbrc.2012.02.008

50. Kwon CH, Moon HJ, Park HJ, Choi JH, Park DY. S100A8 and S100A9 promotes invasion and migration through p38 mitogen-activated protein kinase-dependent NF-кB activation in gastric cancer cells. Mol Cells. (2013) 35:226-34. doi: 10.1007/s10059-013-2269-x

51. Mitsui Y, Tomonobu N, Watanabe M, Kinoshita R, Sumardika IW, Youyi C, et al. Upregulation of mobility in pancreatic cancer cells by secreted S100A11 through activation of surrounding fibroblasts. Oncol Res. (2019) 27:945-56. doi: 10.3727/096504019X15555408784978

52. Kimber I, Cumberbatch M, Dearman RJ, Headon DR, Bhushan M, Griffiths CE. Lactoferrin: influences on Langerhans cells, epidermal cytokines, and cutaneous inflammation. Biochem Cell Biol. (2002) 80:103-7. doi: 10.1139/o01-227

53. Lyons TE, Miller MS, Serena T, Sheehan P, Lavery L, Kirsner RS, et al. Talactoferrin alfa, a recombinant human lactoferrin promotes healing of diabetic neuropathic ulcers: a phase 1/2 clinical study. Am J Surg. (2007) 193:49-54. doi: 10.1016/j.amjsurg.2006.07.010

54. Liu K, Shi H, Peng Z, Wu X, Li W, Lu X. Exosomes from adipose mesenchymal stem cells overexpressing stanniocalcin-1 promote reendothelialization after carotid endarterium mechanical injury. Stem Cell Rev Rep. (2021). doi: 10.1007/s12015-021-10180-4

55. Li G, Zhou LN, Yang H, He X, Duan Y, Wu F. Ninjurin 2 overexpression promotes human colorectal cancer cell growth in vitro and in vivo. Aging. (2019) 11:8526-41. doi: 10.18632/aging.102336

56. Wang DW, Zheng HZ, Cha N, Zhang XJ, Zheng M, Chen MM, et al. Downregulation of AHNAK2 inhibits cell proliferation, migration and invasion 
through inactivating the MAPK pathway in lung adenocarcinoma. Technol Cancer Res Treat. (2020) 19. doi: 10.1177/1533033820957006

57. Kiss T, Jámbor K, Koroknai V, Szász I, Bárdos H, Mokánszki A, et al. Silencing osteopontin expression inhibits proliferation, invasion and induce altered protein expression in melanoma cells. Pathol Oncol Res. (2021) 27:581395. doi: $10.3389 /$ pore. 2021.581395

58. Kim MH, Wu WH, Choi JH, Kim J, Jun JH, Ko Y, et al. Galectin1 from conditioned medium of three-dimensional culture of adiposederived stem cells accelerates migration and proliferation of human keratinocytes and fibroblasts. Wound Repair Regen. (2018) 26(Suppl 1):S9-18. doi: 10.1111/wrr.12579

59. Cerri DG, Rodrigues LC, Alves VM, Machado J, Bastos VAF, Carmo Kettelhut I, et al. Endogenous Galectin-3 is required for skeletal muscle repair. Glycobiology. (2021) cwab071. doi: 10.1093/glycob/cwab071

60. Bellofiore N, Rana S, Dickinson H, Temple-Smith P, Evans J. Characterization of human-like menstruation in the spiny mouse: comparative studies with the human and induced mouse model. Hum Reprod. (2018) 33:1715-26. doi: 10.1093/humrep/dey247

61. Fan X, Krieg S, Kuo CJ, Wiegand SJ, Rabinovitch M, Druzin ML, et al. VEGF blockade inhibits angiogenesis and reepithelialization of endometrium. FASEB J. (2008) 22:3571-80. doi: 10.1096/fj.08-111401

62. Wyatt KA, Filby CE, Davies-Tuck ML, Suke SG, Evans J, Gargett CE. Menstrual fluid endometrial stem/progenitor cell and supernatant protein content: cyclical variation and indicative range. Hum Reprod. (2021) 36:221529. doi: 10.1093/humrep/deab156

63. Salamonsen LA, Zhang J, Hampton A, Lathbury L. Regulation of matrix metalloproteinases in human endometrium. Hum Reprod. (2000) 15(Suppl 3):112-9. doi: 10.1093/humrep/15.suppl_3.112

64. Gaide Chevronnay HP, Selvais C, Emonard H, Galant C, Marbaix E, Henriet P. Regulation of matrix metalloproteinases activity studied in human endometrium as a paradigm of cyclic tissue breakdown and regeneration. Biochim Biophys Acta. (2012) 1824:146-56. doi: 10.1016/j.bbapap.2011. 09.003

65. Koks CA, Groothuis PG, Slaats P, Dunselman GA, de Goeij AF, Evers JL. Matrix metalloproteinases and their tissue inhibitors in antegradely shed menstruum and peritoneal fluid. Fertil Steril. (2000) 73:604-12. doi: 10.1016/S0015-0282(99)00566-X

66. Rohani MG, Parks WC. Matrix remodeling by MMPs during wound repair. Matrix Biol. (2015) 44-46:113-21. doi: 10.1016/j.matbio.2015.03.002

67. Gill SE, Parks WC. Metalloproteinases and their inhibitors: regulators of wound healing. Int J Biochem Cell Biol. (2008) 40:1334-47. doi: 10.1016/j.biocel.2007.10.024

68. Rodgers WH, Osteen KG, Matrisian LM, Navre M, Giudice LC, Gorstein F. Expression and localization of matrilysin, a matrix metalloproteinase, in human endometrium during the reproductive cycle. Am J Obstet Gynecol. (1993) 168:253-60. doi: 10.1016/S0002-9378(12)90922-9

69. Berton A, Selvais C, Lemoine P, Henriet P, Courtoy PJ, Marbaix E, et al. Binding of matrilysin-1 to human epithelial cells promotes its activity. Cell Mol Life Sci. (2007) 64:610-20. doi: 10.1007/s00018-007-6415-5

70. Vincent AJ, Malakooti N, Zhang J, Rogers PA, Affandi B, Salamonsen LA. Endometrial breakdown in women using Norplant is associated with migratory cells expressing matrix metalloproteinase-9 (gelatinase B). Hum Reprod. (1999) 14:807-15. doi: 10.1093/humrep/14.3.807

71. Vincent AJ, Salamonsen LA. The role of matrix metalloproteinases and leukocytes in abnormal uterine bleeding associated with progestinonly contraceptives. Hum Reprod. (2000) 15(Suppl 3):135-43. doi: 10.1093/humrep/15.suppl_3.135

72. Jeziorska M, Salamonsen LA, Woolley DE. Mast cell and eosinophil distribution and activation in human endometrium throughout the menstrual cycle. Biol Reprod. (1995) 53:312-20. doi: 10.1095/biolreprod53.2.312

73. Wen T, Rothenberg ME. The regulatory function of eosinophils. Microbiol Spectr. (2016) 4. doi: 10.1128/microbiolspec.MCHD-0020-2015

74. Kologrivova I, Shtatolkina M, Suslova T, Ryabov V. Cells of the immune system in cardiac remodeling: main players in resolution of inflammation and repair after myocardial infarction. Front Immunol. (2021) 12:664457. doi: $10.3389 /$ fimmu.2021.664457

75. Phillipson M, Kubes $\mathrm{P}$. The healing power of neutrophils. Trends Immunol. (2019) 40:635-47. doi: 10.1016/j.it.2019.05.001
76. Legere SA, Haidl ID, Légaré JF, Marshall JS. Mast cells in cardiac fibrosis: new insights suggest opportunities for intervention. Front Immunol. (2019) 10:580. doi: $10.3389 /$ fimmu. 2019.00580

77. Bozorgmehr M, Gurung S, Darzi S, Nikoo S, Kazemnejad S, Zarnani AH, et al. Endometrial and menstrual blood mesenchymal stem/stromal cells: biological properties and clinical application. Front Cell Dev Biol. (2020) 8:497. doi: $10.3389 /$ fcell.2020.00497

78. Masuda H, Schwab KE, Filby CE, Tan CSC, Tsaltas J, Weston GC, et al. Endometrial stem/progenitor cells in menstrual blood and peritoneal fluid of women with and without endometriosis. Reprod Biomed Online. (2021) 43:3-13. doi: 10.1016/j.rbmo.2021.04.008

79. Greening DW, Nguyen HP, Elgass K, Simpson RJ, Salamonsen LA. Human endometrial exosomes contain hormone-specific cargo modulating trophoblast adhesive capacity: insights into endometrial-embryo interactions. Biol Reprod. (2016) 94:38. doi: 10.1095/biolreprod.115.134890

80. Dalirfardouei R, Gholoobi A, Vahabian M, Mahdipour E, Afzaljavan F. Therapeutic role of extracellular vesicles derived from stem cells in cutaneous wound models: a systematic review. Life Sci. (2021) 273:119271. doi: $10.1016 /$ j.lfs.2021.119271

81. Rohani Ivari J, Mahdipour E. Adipose tissue versus stem cell-derived small extracellular vesicles to enhance the healing of acute burns. Regen Med. (2021) 16:629-41. doi: 10.2217/rme-2020-0199

82. Zhang Y, Pan Y, Liu Y, Li X, Tang L, Duan M, et al. Exosomes derived from human umbilical cord blood mesenchymal stem cells stimulate regenerative wound healing via transforming growth factor- $\beta$ receptor inhibition. Stem Cell Res Ther. (2021) 12:434. doi: 10.1186/s13287-021-02517-0

83. Kadota T, Fujita Y, Araya J, Watanabe N, Fujimoto S, Kawamoto H, et al. Human bronchial epithelial cell-derived extracellular vesicle therapy for pulmonary fibrosis via inhibition of TGF- $\beta$-WNT crosstalk. J Extracell Vesicles. (2021) 10:e12124. doi: 10.1002/jev2.12124

84. Xie Y, Rizzi SC, Dawson R, Lynam E, Richards S, Leavesley DI, et al. Development of a three-dimensional human skin equivalent wound model for investigating novel wound healing therapies. Tissue Eng Part C Methods. (2010) 16:1111-23. doi: 10.1089/ten.tec.2009.0725

85. Malik S, Day K, Perrault I, Charnock-Jones DS, Smith SK. Reduced levels of VEGF-A and MMP-2 and MMP-9 activity and increased TNF-alpha in menstrual endometrium and effluent in women with menorrhagia. Hum Reprod. (2006) 21:2158-66. doi: 10.1093/humrep/del089

86. Ramanathan M, Pinhal-Enfield G, Hao I, Leibovich SJ. Synergistic upregulation of vascular endothelial growth factor (VEGF) expression in macrophages by adenosine $\mathrm{A} 2 \mathrm{~A}$ receptor agonists and endotoxin involves transcriptional regulation via the hypoxia response element in the VEGF promoter. Mol Biol Cell. (2007) 18:14-23. doi: 10.1091/mbc.e06-07-0596

87. Maybin JA, Hirani N, Brown P, Jabbour HN, Critchley HO. The regulation of vascular endothelial growth factor by hypoxia and prostaglandin $\mathrm{F}_{2} \alpha$ during human endometrial repair. J Clin Endocrinol Metab. (2011) 96:2475-83. doi: 10.1210/jc.2010-2971

88. Martínez-Aguilar R, Kershaw LE, Reavey JJ, Critchley HOD, Maybin JA, Hypoxia and reproductive health. The presence and role of hypoxia in the endometrium. Reproduction. (2021) 161:F1-17. doi: 10.1530/REP-20-0268

Conflict of Interest: The author declares that the research was conducted in the absence of any commercial or financial relationships that could be construed as a potential conflict of interest.

Publisher's Note: All claims expressed in this article are solely those of the authors and do not necessarily represent those of their affiliated organizations, or those of the publisher, the editors and the reviewers. Any product that may be evaluated in this article, or claim that may be made by its manufacturer, is not guaranteed or endorsed by the publisher.

Copyright $(02021$ Salamonsen. This is an open-access article distributed under the terms of the Creative Commons Attribution License (CC BY). The use, distribution or reproduction in other forums is permitted, provided the original author(s) and the copyright owner(s) are credited and that the original publication in this journal is cited, in accordance with accepted academic practice. No use, distribution or reproduction is permitted which does not comply with these terms. 